Highlighting Tensions in Recruitment and Selection Research and Practice

\author{
Ann Marie Ryan \\ Michigan State University, USA \\ Eva Derous \\ Ghent University, Belgium
}

Author note

Ann Marie Ryan, Department of Psychology, Michigan State University. Eva Derous, Department of Personnel Management, Work and Organizational Psychology, Ghent University.

Correspondence regarding this article can be addressed to Ann Marie Ryan, Department of Psychology, Michigan State University, East Lansing, MI 48824-1122, USA. E-mail: ryanan@msu.edu.

We acknowledge Brecht Vandeputte for his aid with the trend analysis. 


\begin{abstract}
In this article we highlight five tensions that exist in recruitment and selection (R\&S) research and practice today and that are centered around the "efficiency press" and so-called "researchpractice" gap. Identified tensions are desires for (1) innovation and efficiency, (2) customization and consistency, (3) transparency and effectiveness, (4) wide-reach and coherence, and (5) diversity and standardization. Each tension is illustrated with findings from the five studies of this Special Issue that were presented at the third meeting of the European Network of Selection Researchers (August 2014), and supplemented with empirical data on the research-practice gap in recruitment and selection (period 2009-2013). We consider how we might move forward in addressing the "efficiency press" in research as well as managing these tensions in practice
\end{abstract}




\section{Highlighting Tensions in Recruitment and Selection Research and Practice}

\section{Introduction}

This Special Issue of the International Journal of Selection and Assessment that is dedicated to the third meeting of the European Network of Selection Researchers (ENESER) contains a set of papers that address contemporary challenges in recruitment and selection. This commentary provides a great opportunity to step back and consider some underlying tensions that exist in recruitment and selection $(\mathrm{R} \& S)$ research and practice today that these papers touch upon, and to discuss how we might move forward in addressing (or at least acknowledging) these tensions in research as well as managing them in practice. In particular, much of the challenge in moving from these research papers to practical implementations revolves around ensuring that we manage the "efficiency press" from the practice side of recruitment and selection while moving research forward.

Managing the efficiency press touches upon the so called "research-practice gap" in R\&S whereby what is important in practice (e.g., efficient use of applicant time, processing of higher volumes of applicants) is not the focus of researchers, and what has been uncovered by researchers is not implemented by those in practice. In the past fifteen years, several attempts have been made to investigate the research-practice gap in human resources (HR) and $R \& S$ specifically, by either asking professionals about trends in R\&S (e.g., Lievens, Van Dam, \& Anderson, 2002) or by reviewing I-O psychology literature in both academic journals and popular HR magazines (e.g., Cascio \& Aguinis, 2008; Deadrick \& Gibson, 2007; Deadrick \& Gibson, 2009). For instance, Lievens et al. (2002) asked 26 Flemish HR professionals to list all trends they deemed important in $R \& S$ and then discussed these topics based on the current stateof-the-art in the I-O psychology literature. More recently, Cascio and Aguinis (2008) performed 
a 45-year (1963-2007) content analysis on topics that were investigated and published in two leading I-O psychology journals (the Journal of Applied Psychology and Personnel Psychology). A similar endeavor was undertaken by Deadrick and Gibson (2009) over a 30-year period of time (1976-2005). In this commentary, we will highlight tensions that the articles from this Special Issue illustrate, supplemented with empirical data we gathered on the research-practice gap in R\&S. Below, we briefly explain how we investigated both practitioners and researchers’ perspectives on $R \& S$, before we illustrate five identified tensions.

\section{From Street Credibility to Scientific Validity}

Trends are defined as general, new directions in which a domain (like I-O psychology) or topic (like R\&S) is developing or changing. Until the mid-1900s, "trends" (in literature, architecture, science, fashion, music, or any other societal domain) were typically attributed to and -most likely- also set by a few great minds, prominent designers, or researchers. For instance, inspired by Christian Dior's "New Look” style in haute couture (1947), cognitive psychologist Jerome Bruner launched around the same time his "New Look Psychology", being a heady liberation in perception psychology (Boden, 2006). These days, new developments or perspectives are much less ascribed to single great minds or designers but rather come "from the street." As researchers and practitioners, we shape our world and create developments ourselves by interpreting events and combining things we have seen, discussed, and/or experienced in our communities. These are picked-up by so-called "trend watchers" who observe and interview people on the street, and then spread "new trends" through (social) media and (online/offline) communities. Hence, as in fashion, music, architecture, and other fields, trends in R\&S also have "street credibility" as they are created by the community of R\&S practitioners. However, moving 
from "street credibility" to "scientific validity" is still a big step and what the research-practice divide is about.

Acting somewhat as "trend watchers", in a first phase, we questioned 165 Flemish human resource (HR) professionals from diverse organizations (16.36\% governmental organizations; $30.91 \%$ HR consultancy; $39.39 \%$ profit organizations, and $10.91 \%$ social profit organizations). We asked these HR professionals to list and rank-order the three most important trends they faced in their professional practice as related to HR in general, and to R\&S specifically. Trends were described as "those practices or aspects related to both $H R$ and $R \& S$ that are deemed important at the moment as well as for the near future in order to make any significant change, contribution, and/or improvement to their business." In total, $165 \mathrm{HR}$ professionals $(38.18 \%$ women; $M$ age $=37.03$ year, $S D$ age $=10.32 ; M$ work experience $=8.88$ year, $S D$ work experience $=7.84$ ) reported 498 trends related to HR (excluding R\&S aspects), and 442 trends related to R\&S. Subsequently, trends were content analyzed and classified according to Deadrick and Gibson (2009) adjusted taxonomy on HR-related topics (see further).

In a second phase, a content analysis was performed on 2600 papers related to HR (in general) and 447 papers on recruitment and selection that had been presented at the annual SIOP conferences from 2009 till 2013. These papers were also classified according to Deadrick and Gibson's (2009) adjusted taxonomy (i.e., complemented with SIOP's annual conference topics).

Finally, we calculated the proportions of "trends" listed by HR professionals and the proportion of area topics presented at SIOP conferences. This was followed by a series of Spearman correlation coefficients and Z-tests to examine whether proportions of trends differed significantly across practitioners (i.e., reported trends) and researchers (i.e., accepted/presented papers at the SIOP conferences). In this way, we wanted to touch upon any tensions or gaps 
practitioners and researchers face in what is their current greatest foci. Table 1 summarizes

findings related to R\&S topics, which is the focus of the present commentary (see Appendix for a description of key terms).

In what follows, we discuss five tensions as identified in the papers from this Special Issue and we illustrate them with some findings from the "trend analysis" as outlined above.

(Insert Table 1 about here)

\section{Tension \#1: Desire for Innovation and Desire for Efficiency}

The paper on Conditional Reasoning Tests (CRT) by Galić (2016) highlights a first identified tension in $R \& S$ research and practice around meeting desires (or even demands) for innovation while also meeting desires for efficiency (i.e., the amount of tangible and intangible resources it takes to do something). Practitioners would love to have new and better ways of assessing hard-to-get-at constructs, like propensity to be deviant. Research on CRTs has shown considerable promise for the methodology, and this paper adds to that body of research.

However, as the author notes there is the ever-present tension because "the CRT-A is more time consuming and more labor intensive on applicants than "ordinary" personality measures." (Galić, 2016, p. xx). The paper goes on to show why that loss in efficiency would be worthwhile in terms of validity and faking.

We see this tension between trying to innovate while still meeting organizational concerns about efficiency as a general challenge to those working on selection tool development and to some extent in recruitment as well. Researchers have noted that the cost of a selection procedure is typically negatively correlated with use or intent to use (König, Klehe, Berchtold, \& Kleinmann, 2010). Indeed, if one looks over the technological innovations in the past decade such as the widespread use of computer-adaptive testing, unproctored internet testing, and 
mobile testing, there are more innovations related to efficiency (less applicant time, no need for proctors, less administrative expense) than to innovations related to assessing "new" constructs or "old" constructs in new ways. Results from the analysis on general HR trends mentioned earlier show that trends related to producing an efficient organized "HR department" (i.e., lean, results-oriented and cost-effective; $z=13.50, p<.01$ ) is high on HR practitioners' agendas in general.

Interestingly, we noted a strong focus in research conference presentations on “assessment" topics $(z=-9.21, p<.01$; like conditional reasoning tests, situational judgment tests, etc.), meaning that issues like the construct validity of tests, seem less of an issue to practitioners than to researchers. Hence, striving for efficiency may also come at a cost when resulting in less effective $R \& S$ practices.

What is needed to move $R \& S$ research and practice forward while still managing this tension? First, we need to consider how to encourage innovation. While those on the consulting side may be most concerned with in-house innovation and proprietary ideas, the field as a whole, and researchers in particular, should be more generally focused on how can we encourage generation of novel ideas. Those in product development have noted that innovation is a process that can be managed, and the field of R\&S might seek to think in these terms. As one example, innovation contests or tournaments are common in tech fields where individuals or teams submit designs or prototypes related to solving a specific problem (Yücesan, 2013). Platforms that organize such contests include crowdspring.com, 99designs.com, and InnoCentive (Terwiesch, $\& \mathrm{Xu}, 2008$ ). While granting agencies might be seen as innovation tournament conductors (i.e., they solicit ideas around problems and reward researchers with money to execute the most promising ideas), most government granting agencies do not venture far into the types of 
questions that selection system developers and recruiters are most concerned with. For example, suppose we held a tournament on minimizing faking in self-report measures in selection contexts (while forced-choice multidimensional personality measures are emerging as a winner, perhaps there are other ideas out there that have not gained traction) or on ways to assess deviance propensity (as the CRT-A addresses; Galić, 2016).

Second, we need to recognize the differences between development research and translational research and be willing to provide outlets for publishing each. That is, when developing and testing a new idea there may be large inefficiencies. Moving from that idea to something that can be not only implemented but that is scalable for large numbers of applicants is a different type of research. Thus, even in areas where researchers and practitioners are relatively aligned in priorities (e.g., recruitment was a top ranked topic across both groups; see Table 1) we may not be seeing research translated to practice because it is not yet considered a scalable or efficient idea. One example may be scenario-based studies conducted among student populations that cannot be translated easily to recruitment practices that target a much wider audience due to a lack of ecological validity (see Breaugh, 2013; Vanderstukken, Van den Broeck, \& Proost, 2016, in this issue). The reverse, however, seems equally the case: Table 1 suggests some recruitment practices that aim to increase efficiency (the use of video resumes and social media; Hiemstra \& Derous, 2015) are more a focus for practitioners but remain somewhat less of a focus by researchers $(z=13.94, p<.01$; see also Hiemstra, Derous, \& Born, 2015 in case of video resumes).

Third, we need to continue to research what applicants find acceptable - while screening individuals with 10 questions in 5 minutes may seem like an ultimate goal for efficiency (e.g., Kruyen, 2015), losing applicants who feel that not enough thought is put into the hiring process 
is equally problematic. Perhaps a longer process is acceptable if explained well, if engaging, and if job relevant. Some tools that seem very efficient at first sight (like word-of-mouth recruitment, see the paper of Van Hoye, Weijters, \& Lievens, and the paper on assessment center exercises of Jacksch \& Klehe, both in this issue) might be far less effective if applicants find out about source characteristics (like employee referral bonus programs in word-of-mouth recruitment and information about dimensions tested in assessment center exercises). That is, applicants value efficiency only to a point. What also matters and needs to be taken into account is the "social validity" of procedures, i.e., how applicants react to R\&S practices (e.g., informativeness, participation, transparency, and feedback; see Schuler, 1993). Results from the trend analysis, however, showed that researchers seem to pay more attention to applicant reactions than practitioners do $(z=-3.56, p<.01)$. This was much more often a topic of focus in research than its rank by practitioners might indicate, which is consistent with findings of König, Jöri, and Knüsel (2011) who found that Swiss practitioners did not mention "applicant reactions" in their cognitive maps of selection. In this case, we think this may be because research is lagging practice - attending to applicant reactions is already seen as important by practitioners and not a trend.

\section{Tension \#2: Desire for Customization and Desire for Consistency}

One of the key advances afforded by technological innovation in recruitment is customization (see Dineen \& Allen, 2014, for a review). The paper by Vanderstukken et al. in this issue raises the question of how organizations might decide what images to present to attract different types of people. The paper on word-of-mouth by Van Hoye et al. (2016) also touched upon what information matters to whom. Other recruitment research has also supported how some aspects may be universally valued (Catanzaro, Moore, \& Marshall, 2010; Judge \& Bretz, 
1992; Ravlin \& Meglino, 1987) and others (e.g., work-life policies, social responsibility) appeal to particular segments (Casper, Wayne, \& Manegold, 2013; Gully, Phillips, Castellano, Han, \& Kim, 2013; Tsai, Joe, Lin, \& Wang, 2014; Zhang \& Gowan, 2012). Thus, research in this issue and elsewhere suggests the value of customization in recruitment, and technology allows for that customization in practice.

What R\&S practice has moved toward is a strategy known as mass customization, or providing a high degree of personalization while reaching economies of scale at the production end (Tseng \& Jiao, 2001). That is, in recruitment we have the technological capabilities to allow visitors to career pages to choose what information to examine, to explore content tailored to them personally. For example, fit assessment tools serve as a means of asking "customers" or job applicants what they are seeking in a job and assess what works best (Kraichy \& Chapman, 2013; see Ikea's website for a good example:

http://www.ikea.com/ms/en_US/rooms_ideas/fitquiz09/). In selection assessments, consultants have long offered customizable test batteries to client organizations so as to allow assessing relevant constructs and avoiding less relevant testing (once again, largely driven by the press for efficiency).

Can we enhance our understanding of recruitment through research on customization? Considering that Uggerslev, Fasina, and Kraichy's (2012) meta-analysis showed that fit is the strongest predictor of applicant attraction, research on the best approaches to customizing recruitment information should be particularly valuable to more effective and more efficient recruitment. Could we enhance understanding of assessment through research on better methods for determining what we need to assess in which candidates? A crude example would be determining there is no need to assess certain types of knowledge for candidates with a certain 
number of years of experience in an area, but giving knowledge assessments to those with less experience. Doing such adaptive assessment at the test rather than item level may have downsides (i.e., lack of standardization and potential adverse impact) but could have upsides associated with both validity and efficiency. Interestingly, König et al. (2011) addressed customization as a key way practitioners think about selection, i.e., whether a procedure is useful for certain jobs and not others, whether it should be given early in a process or later. They noted that one unanswered question is why specific beliefs about "to whom" and "when" arise; we think they might be upended by thinking of customization more broadly.

As we continue down this path of customization, it is important to keep in mind some of the nuances of mass customization and the variants that may lead to unneeded complexity and customizing in ways that applicants do not value. In terms of types of customization identified by Gilmore and Pine (1997), fit assessments might result in what they label as a collaborative customization where applicants are asked to articulate their needs and then recruitment information is provided to address what they request. Practitioners also engage in what is termed an adaptive customization (one standard product that can be altered by users, such as with choosing to administer only portions of a suite of assessments) or cosmetic customization (standard product packaged differently, such as contextualizing assessment questions for specific industries of jobs). Targeted recruitment falls more in line with what they call transparent customization, where applicant behaviors/values/needs are observed and offerings are modified without having to directly interact with the applicant (e.g., recruitment ads seen on search engines by only certain segments). Each of these forms of customization may have value for a variety of R\&S practices, but their effects need to be researched. 
Remarkably, customization was not stressed much in the trend analysis: Only $1.42 \%$ of trends mentioned by HR professionals related to targeted recruitment and another $2.84 \%$ related to providing flexible employment conditions (1.42\%) and the importance of assessing "personorganization" fit (1.42\%). One way researchers could better address this gap and manage this tension would be by tracking and evaluating what customization is going on and what the effectiveness of these efforts is, as well as by exploring possibilities in customization and where they may or may not add value.

\section{Tension \#3: Desire for Transparency and Desire for Effectiveness}

The third tension we noticed is meeting desires for transparency while also meeting desires for effectiveness (i.e., producing high-quality results). Jacksch and Klehe's paper on transparency and Oostrom and De Soete's paper on self-serving attributions for ethnic applicants both illustrate that information is not always a good thing for everyone (i.e., it may create threat, it may lead to more defensive attributions). A key concern then is how to be transparent and honest without negatively affecting outcomes for underrepresented groups. Further, the Van Hoye et al. paper in this issue also touches on how transparency (e.g., finding out that an employee is being paid to generate positive word-of-mouth) can have negative effects.

Transparency is touted as a critical part of a trusting organizational climate (e.g., Schnackenberg \& Tomlinson, 2014). Some have noted that transparency should not be taken to mean complete disclosure (Cuthbertson \& Harris, 2014) and it should be clear what might not be shared (e.g., the scoring key to an assessment). However, the studies here hint at how information can change how an individual performs in the hiring process and/or how he/she interprets performance going forward in a job search. That is, can honesty have negative 
consequences for individuals if it creates threat, damages self-esteem, or allows for ultimately detrimental attributional reasoning?

Another downside to transparency efforts may be information overload for both the applicant and the recruiter. Research on how recruitment messages, assessment instructions, candidate information and the like affect cognitive load might prove valuable in considering how to balance informativeness with stress-inducing cognitive processing demands in the applicant and the recruiter (e.g., Buijsrogge, Duyck, \& Derous, 2015; Derous, Buijsrogge, Roulin, \& Duyck, 2015, on processing candidate information in interviews).

The paper by Galić (2016) on the conditional reasoning test on aggression also highlights another tension around meeting desires to be transparent and effective. If test criteria are transparent to applicants, the tests' overall effectiveness can be jeopardized because of job applicants' response tendencies (like social desirable responding). As self-ratings are subject to a variety of ego-enhancing biases, researchers in HRM and OB started turning their attention to more implicit measures (like conditional reasoning tests, e.g., DeSimone \& James, 2015). Implicit measures differ from explicit tools in that applicants may not be aware of the constructs being measured (unless they learned what the test is about). It is assumed that behavior can be triggered through implicit processing outside of applicants' conscious awareness. Some argue that the use of implicit measures in HR and OB seems rather a question of how and not if (e.g., Becker \& Mengers, 2013). Yet, research on effectiveness in selection contexts is relatively nascent (e.g., psychometric properties; see Galić, 2016). As there are different types of implicit measures ( e.g., from CRTs to biological measures), their practicality (e.g., taking saliva samples vs. administering CRTs), and acceptability (e.g., applicant reactions like perceived job relevance and face validity) warrant further investigation. 


\section{Tension \#4: Desire for Wide-reach and Desire for Coherence}

The fourth tension is about the desire to make all employees recruitment ambassadors and the desire to maintain coherence in recruitment at the same time. In their paper in this issue, Van Hoye et al. provide research that highlights challenges associated with the trend to involve more employees in recruitment so as to tap into as many connections as possible. While organizations have recognized that employee social media presence and social networks are important in recruitment, there is a continued need for research on how to effectively maintain coherence in message and strategy where all employees are brand ambassadors. The Van Hoye et al. work on financial incentives for word-of-mouth provides one illustration of evaluating the success of this strategy. Currently, recruitment is at a nexus between the positive value of a wide range of information available for both job seekers and organizations, and the increased filtering and editing of that information. That is, people are definitely more concerned about their online images as job seekers than in the past and work assiduously to cultivate a certain social presence; companies hire others to monitor and clean up their social presence and to promote their social score.

Although our trend analysis showed that both practitioners and researchers find novel recruitment practices (such as social media, e-recruitment, employer branding, war for talent, internal recruitment, and use of referrals) rather important (as shown by their similar rankings), there was still a significant difference in amount of attention paid by practitioners and academics to these issues $(z=13.94, p<.01)$. Recruitment issues seemed more of a concern to practitioners when we compared the number of statements made by practitioners to the number of papers presented at SIOP conferences (2009-2013). Interestingly, Cascio and Aguinis (2008) reported relatively few papers on recruitment issues being published in leading I-O psychology journals 
between 1963 and 2007 (i.e., 0.97\% of topics published in the Journal of Applied Psychology papers and a comparable $2.49 \%$ of Personnel Psychology papers) with a slight increase in the number of publications on recruitment from 2003 to 2007 (i.e., 1.53\% of Journal of Applied Psychology papers; $5.41 \%$ of Personnel Psychology papers). This trend may have changed as more attention is recently being paid to recruitment issues by researchers (see $\mathrm{Yu}$ and Cable, 2014, for a review). Researchers indeed consider the changed recruitment function and the changes in recruitment roles in organizations in order to close this research-practice gap.

\section{Tension \#5: Desire for Diversity and Desire for Standardization}

For many years, both researchers and practitioners have focused on ways to reduce adverse impact in hiring processes. Note that while Table 1 shows a gap between practitioner views on diversity issues as a trend and its rank among scientific conference topics, in both cases diversity issues are near the top of lists in terms of important trends and the focus of research. Both the Jacksch and Klehe and the Oostrom and De Soete papers in the Special Issue continue this focus. However, they also point to the tension that can arise when standardization and consistency with what applicants and employers have come to expect from hiring processes do not line up with what might be most promotive of diversity in the workforce. Specifically, the Jacksch and Klehe paper showcases whether attending to stereotype threat effects on some candidates might lead us to make different choices about how selection is approached. Ryan and Sackett (2013) noted that many of the methods for reducing stereotype threat supported by research would not be considered feasible or appropriate in hiring contexts (e.g., telling applicants that a group difference does not exist (stereotype nullification) when it fact it does, such as gender differences on a test of mathematical ability; stating that the assessment is not diagnostic, when it is indeed supported by validity evidence and about to be used in decision 
making; testing in a same group environment; asking individuals to write a self-affirmation statement prior to testing). Further, one challenge in attempting to address any stereotype threat in an assessment environment is that interventions must occur within the context of standardization and consistency across individuals. Thus, investigating whether certain aspects of $\mathrm{R} \& \mathrm{~S}$ processes induce stereotype threat is critical, but this investigation must also recognize and research the practical constraints and unintended consequences of mitigation.

We should also note that the desire for standardization, despite being a basic element of procedural justice and often advised for legality, ease of administration, and validity reasons, is not universal in practice. König et al. (2011) noted that about one third of the practitioners they interviewed preferred unstandardized selection processes. Hence, understanding when and under what aspects and for what purposes the desire for standard approaches does and does not exist (e.g., evaluating CEO candidates) can be important to understand how this tension highlighted here plays a role or not.

\section{Conclusion}

Our aim in highlighting these tensions is not to suggest how they can be resolved, but rather to understand what their role is in how we approach practice and how what we research can be recognized and appreciated. We have noted here that some of these tensions play into gaps that can be seen between what R\&S researchers are focusing on and what practitioners are seeing as key trends that should be attended to. Rynes (2012) summarizes the nature of researchpractice gaps in terms of lack of practitioner awareness of research findings, differences in beliefs in credibility of research findings, and lack of implementation of findings. We believe the tensions described may touch upon all of these; still we noted in our discussion of the tensions that more can be done to share knowledge in ways that encourage its use. 
While we highlighted some differences in focus of researchers and practitioners, we should note that $\mathrm{R} \& \mathrm{~S}$ is an area that sometimes has been considered as having a smaller research-practice gap than others (e.g., Deadrick \& Gibson, 2009 when content-analyzing articles published in HR-focused journals 1976-2005), but in other publications as having the largest gap of HR fields (Rynes, 2012). Examples of areas that showed no gap in our dataset were specific tools (like interviews), international/global issues, and technology issues. Importantly, no differences in overall ranking of R\&S topics was found (Spearman $r_{s}=.722, p<$ $.01)$, so that in general, practitioners paid the same amount of attention to R\&S topics, in line with the conclusions of Deadrick and Gibson (2009). Our aim in this commentary is to note that even with small or no gaps in topic focus, there are still differences in criteria for finding work of value. That is, research may not be implemented if it is not seen as efficient, it is not sufficiently transparent, and it does not enhance diversity, regardless of the quality of the work. Similarly, questions of interest in practice related to maximizing reach, customizing, or efficiency may be viewed as not theory-advancing or novel by the research community.

There are notable differences between our approach and previous studies on the researchpractice gap (e.g., Deadrick \& Gibson, 2007, 2009) in that we compared trends listed by a large group of HR professionals to research topics presented at I-O conferences (SIOP; ENESER). However, there are limitations to our observations here, which stemmed from the papers in this issue and the trend analysis. Trends by definition are dynamic in nature and evolve. Typically, trend analyses compare data over time to identify any (in)consistent patterns, which we did only to a certain extent (e.g., comparing SIOP area topics over five years). Trends identified from practitioners, for instance, were measured at a single point in time. So we only provided a static picture or 'snapshot' of trends and we recognize that their continued change means our data can 
be outdated before publication. We categorized trends for purpose of analysis, but the category labels themselves do not convey what the specific trends are (e.g., use of Facebook in recruiting may be considered as the trend, not "recruitment"). Also, the trends identified are limited to Flemish HR professionals. While we do not expect large differences compared to other WesternEuropean HR professionals, R\&S issues are also embedded in a very local setting (contextbounded) as they are closely tied to local labor market dynamics and legislative issues.

In terms of moving forward while recognizing some of the tensions highlighted in the articles in this Special Issue, we can think about evidence-based R\&S practice. According to Rousseau this is about "taking professional decisions away from personal preference and unsystematic experience toward those based on the best available scientific evidence" (Rousseau, 2006, p. 256). To do so, researchers could continue to identify trends and gaps by using surveys or more qualitative approaches (e.g., König et al., 2011). Greater discussion of how to manage tensions by both practitioners and researchers would be most useful.

Rynes, Giluk, and Brown (2007) illustrated that practitioner and "bridge" publication outlets seldom cover topics that are considered important HR findings and when they do so, do not cover the topics in ways consistent with the research evidence base. One might take a deeper dive in terms of this Special Issue: Are these topics covered in practitioner outlets? If so, what is the quality of the coverage? What sources of evidence are relied upon in discussing these topics in those outlets? As one example, Sackett, Hardison, and Cullen (2005), note the problematic coverage of stereotype threat in mainstream outlets. Rynes et al. (2007) also challenge HR researchers to do work that is of interest and relevance to these in practice as well as to communicate it to practice audiences. Those are worthy challenges for R\&S researchers in particular to embrace. 
Rynes (2012) offered a number of potential solutions to reducing gaps by increasing awareness of research, believability of findings, and implementation (see her Table 13.2 for a summary). We agree wholeheartedly with her suggestions, many of which are about communication of research findings and the topic focus of research. We would add specifically to those in $R \& S$ research space to consider the tensions we note here - as well as others that exist in $\mathrm{R} \& \mathrm{~S}$ practice - more directly in how we approach our research. Doing so should make our research more relevant, credible, and useful. 


\section{References}

Becker, W. J., \& Mengers, J. I. (2013). Biological implicit measures in HRM and OB: A question of how not if. Human Resource Management Review, 23, 219-228. doi: 10.1016/j.hrmr.2012.12.003

Boden, M. A. (2006). Mind as machine. A history of cognitive science (Vol. 1). Oxford: Oxford University Press.

Breaugh, J. A. (2013). Employee recruitment. Annual Review of Psychology, 64, 389-416. doi: 10.1146/annurev-psych-113011-143757

Buijsrogge, A., Duyck, W., \& Derous, E. (2015). Interviewbias bij sollicitanten met een stigma: een duaalproces-benadering [Bias in interview judgments of stigmatized applicants: A dual process approach.] Gedrag \& Organisatie, 28, 30-51.

Cascio, W. F., \& Aguinis, H. (2008). Research in industrial and organizational psychology from 1963 to 2007: Changes, choices, and trends. Journal of Applied Psychology, 93, 1062-1081. doi: 10.1037/0021-9010.93.5.1062

Casper, W. J., Wayne, J. H., \& Manegold, J.G. (2013). Who will we recruit? Targeting deepand surface-level diversity with human resource policy advertising. Human Resource Management, 52, 311-332. doi: 10.1002/hrm.21530

Catanzaro, D., Moore, H., \& Marshall, T. R. (2010). The impact of organizational culture on attraction and recruitment of job applicants. Journal of Business and Psychology, 25, 649662. doi: 10.1007/s10869-010-9179-0.

Cuthbertson, M., \& Harris, L. (2014). Jobseekers demanding transparency. Canadian HR Reporter, 27, 10. 
Deadrick, D. L., \& Gibson, P. A. (2007) An Examination of the research-practice gap in HR: Comparing topics of interest to HR academics and HR professionals. Human Resource Management Review, 17, 131-139. doi: 10.1016/j.hrmr.2007.03.001

Deadrick, D. L., \& Gibson, P. A. (2009). Revisiting the research-practice gap in HR: Comparing topics of interest to HR academics and HR professionals. Human Resource Management Review, 19, 144-153. doi: 10.1016/j.hrmr.2009.01.001.

Derous, E., Buijsrogge, A., Roulin, N., \& Duyck, W. (2015). Why your stigma isn't hired: A dual-process framework of interview bias. Human Resources Management Review. doi: 10.1016/j.hrmr.2015.09.006

DeSimone, J. A., \& James, L. R. (2015). An item analysis of the conditional reasoning test of aggression. Journal of Applied Psychology. Advance online publication. doi: 10.1037/apl0000026

Dineen, B. R., \& Allen, D. G. (2014). Internet recruiting 2.0: Shifting paradigms. In K. Y. T. Yu, \& D. M. Cable (Eds.), The Oxford Handbook of Recruitment (pp. 382-401). New York: Oxford University Press.

Galić, Z. (2016). Conditional Reasoning Test for Aggression: Further evidence about incremental validity. International Journal of Selection and Assessment, xx, xx-xx. doi: $\mathrm{xxx}$

Gilmore, J. H., \& Pine, B. J. (1997). The four faces of mass customization. Harvard Business Review, 75, 91-101.

Gully, S. M., Phillips, J. M., Castellano, W. G., Han, K., \& Kim, A. (2013). A mediated moderation model of recruiting socially and environmentally responsible job applicants. 
Personnel Psychology, 66, 935-973. doi: 10.1111/peps.12033

Hiemstra, A. M. F., \& Derous, E. (2015). Video résumés portrayed: Findings and challenges.

In I. Nikolaou en J. K. Oostrom (Eds.), Employee Recruitment, Selection, and Assessment: Contemporary issues for theory and practice (pp. 45-60). New York, NY: Psychology Press/Taylor \& Francis.

Hiemstra, A. M. F., Derous, E., \& Born, M. Ph. (2015). Eerlijkheid van selectie op basis van papieren en video cv's. [Fairness on selection based on paper and video résumés.] Gedrag \& Organisatie, 28, 262-277.

Jacksch, V., \& Klehe, U.-C. (2016). Unintended consequences of transparency during personnel selection: Benefitting some candidates, but harming others? International Journal of Selection and Assessment, xx, $\mathrm{xx}-\mathrm{xx}$. doi: $\mathrm{xx}$.

Judge, T. A., \& Bretz, R. D. (1992). Effects of work values on job choice decisions. Journal of Applied Psychology, 77, 261-271. doi: 10.1037/0021-9010.77.3.261

König, C. J., Jöri, E., \& Knüsel, P. (2011). The amazing diversity of thought: A qualitative study on how human resource practitioners perceive selection procedures. Journal of Business and Psychology, 26, 437-452. doi: 10.1007/s10869-010-9199-9.

König, C.J., Klehe, U.-C., Berchtold, M., \& Kleinmann, M. (2010). Reasons for being selective when choosing personnel selection procedures. International Journal of Selection and Assessment, 18, 17-27. doi: 10.1111/j.1468-2389.2010.00485.x

Kraichy, D., \& Chapman, D. S (2014). Tailoring web-based recruiting messages: Individual differences in the persuasiveness of affective and cognitive messages. Journal of Business and Psychology, 29, 253-268. doi: 10.1007/s10869-013-9311-z 
Kruyen, P. (2015). Wanneer is kort te kort? Over de geschiktheid van korte test om selectie beslissingen te nemen. [When short is too short: The suitability of using short psychological tests for personnel selection.] Gedrag \& Organisatie, 28, 52-70.

Lievens, F., van Dam, K., \& Anderson, N. (2002). Recent trends and challenges in personnel selection. Personnel Review, 31, 580-601. doi: 10.1108/00483480210438771

Oostrom, J. K., \& De Soete, B. (2016). Ethnic differences in perceptions of cognitive ability tests: The explanatory role of self-serving attributions. International Journal of Selection and Assessment, $x x, \mathrm{xx}-\mathrm{xx}$. doi: $\mathrm{xxx}$

Ravlin, E. C., \& Meglino, B. M. (1987). Effect of values on perception and decision making: A study of alternative work values measures. Journal of Applied Psychology, 72, 666-673. doi: $10.1037 / 0021-9010.72 .4 .666$

Rousseau, D. M. (2006). Is there such a thing as "evidence based management"? Academy of Management Review, 31, 256-269. doi: 10.2307/20159200

Ryan, A. M., \& Sackett, P. R. (2013). Stereotype threat in assessments. In K. F. Geisinger, B. A. Bracken, J. F. Carlson, J. C. Hansen, N. R. Kuncel (Eds). APA Handbook of Testing and Assessment in Psychology: Test Theory and Testing and Assessment in Industrial and Organizational Psychology (Vol 1., pp. 661-673). Washington DC: American Psychological Association.

Rynes, S. L. (2012). The research-practice gap in I/O psychology and related fields: Challenges and potential solutions. In S. W. Kozlowski (Ed.), The Oxford Handbook of Organizational Psychology (Vol. 1, pp. 409-454). New York: Oxford University Press.

Rynes, S. L., Giluk, T. L., \& Brown, K. G. (2007). The very separate worlds of academic and practitioners periodicals in human resource management: Implications for evidence - based 
management. Academy of Management Journal, 50, 987-1008. doi:

10.5465/AMJ.2007.27151939

Sackett, P. R., Hardison, C. M., \& Cullen, M. J. (2005). On interpreting research on stereotype threat and test performance. American Psychologist, 60, 271-272. doi: 10.1037/0003066X.60.3.271

Schnackenberg, A. K., \& Tomlinson, E. C. (2014). Organizational transparency: A new perspective on managing trust in organization-stakeholder relationships. Journal of Management. Advance online publication. doi: 10.1177/0149206314525202

Schuler, H. (1993). Social validity of selection situations: A concept and some empirical results. In H. Schuler, J. L. Farr, \& M. Smith (Eds.), Personnel selection and assessment: Individual and organizational perspectives (pp. 11-26). Hillsdale, UK: Lawrence Erlbaum Associates, Inc.

Terwiesch, C., \& Xu, Y. (2008). Innovation contests, open innovation, and multiagent problem solving. Management Science, 54, 1529-1543. doi: 10.1287/mnsc.1080.0884

Tsai, Y., Joe, S, Lin, C., \& Wang, R (2014). Modeling job pursuit intention: Moderating mechanisms of socio-environmental consciousness. Journal of Business Ethics, 125, 287298. doi: 10.1007/s10551-013-1919-4

Tseng, M. M., \& Jiao, J. (2001). Mass Customization. In G. Salvendy (Ed.), Handbook of Industrial Engineering, Technology and Operation Management ( $3^{\text {rd }}$ Ed., pp. 684-709). New York: Wiley.

Uggerslev, K.L., Fassina, N. E., \& Kraichy, D. (2012). Recruiting through the stages: A metaanalytic test of predictors of applicant attraction at different stages of the recruiting process. Personnel Psychology, 65, 597-660. doi: 10.1111/j.1744-6570.2012.01254.x 
Vanderstukken, A., Van den Broeck, A., \& Proost, K. (2016) For love or for money: Intrinsic and extrinsic value congruence in recruitment. International Journal of Selection and Assessment, $x x$, xx-xx. doi: $\mathrm{xxx}$

Van Hoye, G., Weijters, B., \& Lievens, F. (2016). Social influences in recruitment: When is word-of-mouth most effective? International Journal of Selection and Assessment, xx, xx-xx. doi: $\mathrm{xxx}$

Yu, K. Y. T., \& Cable, D. M. (2014). The Oxford Handbook of Recruitment. New York: Oxford University Press.

Yücesan, E. (2013). An efficient ranking and selection approach to boost the effectiveness of innovation contests. IIE Transactions, 45,751-762. doi:10.1080/0740817X.2012.757679

Zhang, L., \& Gowan, M. A. (2012). Corporate social responsibility, applicants' individual traits, and organizational attraction: A person-organization fit perspective. Journal of Business Psychology, 27, 345-362. doi: 10.1007/s10869-011-9250-5 
Table 1

Trends in Recruitment and Selection as Listed by Practitioners and Presented at the SIOP Conferences 2009-2013

\begin{tabular}{|c|c|c|c|c|c|c|c|c|}
\hline \multirow[b]{2}{*}{ Category } & \multicolumn{3}{|c|}{ Practice } & \multicolumn{3}{|c|}{ Research } & \multirow[b]{2}{*}{$Z$} & \multirow[b]{2}{*}{$p$} \\
\hline & $n$ & $\%$ & Rank & $n$ & $\%$ & Rank & & \\
\hline Recruitment & 225 & 50.90 & 1 & 37 & 8.28 & 3 & 13.94 & $<.01$ \\
\hline Assessment & 82 & 18.55 & 2 & 213 & 47.65 & 1 & -9.21 & $<.01$ \\
\hline Diversity & 28 & 6.33 & 3 & 51 & 11.41 & 2 & -2.66 & $<.01$ \\
\hline Selection in general & 24 & 5.43 & 4 & 29 & 6.49 & 4 & -.66 & .50 \\
\hline Interviews & 16 & 3.62 & 5 & 19 & 4.25 & 6 & -.48 & .63 \\
\hline Technology issues & 12 & 2.71 & 6 & 11 & 2.46 & 8 & .24 & .81 \\
\hline Job analysis & 12 & 2.71 & 6 & 29 & 6.49 & 4 & -2.68 & $<.01$ \\
\hline Job choice & 12 & 2.71 & 6 & 8 & 1.79 & 10 & .93 & .35 \\
\hline Job search & 11 & 2.49 & 7 & 14 & 3.13 & 7 & -.58 & .56 \\
\hline Contingent employees & 8 & 1.81 & 8 & 3 & 0.67 & 12 & 1.54 & .12 \\
\hline International/global issues & 5 & 1.13 & 9 & 4 & 0.89 & 11 & .35 & .73 \\
\hline Biographical data & 4 & 0.90 & 10 & 9 & 2.01 & 9 & -1.38 & .17 \\
\hline Applicant reactions & 3 & 0.68 & 11 & 20 & 4.47 & 5 & -3.56 & $<.01$ \\
\hline
\end{tabular}




\section{Appendix}

\begin{tabular}{|c|c|}
\hline Category & Keywords \\
\hline Recruitment & $\begin{array}{l}\text { Social media, E-recruitment, employer branding, war for talent, internal recruitment, referrals, active } \\
\text { recruiting, measurement (tools) }\end{array}$ \\
\hline Assessment & $\begin{array}{l}\text { Abilities, ability testing, personality assessment, physical ability testing, situational judgment test, } \\
\text { assessment center, cognitive ability test, conditional reasoning test, neuropsychological intelligence } \\
\text { tests, knowledge test, in basket test, psychomotor ability, work samples, simulation test, case study, } \\
\text { faking/cheating }\end{array}$ \\
\hline Diversity & Diversity, discrimination, adverse impact \\
\hline Selection in general & $\begin{array}{l}\text { Person-organization fit, selection decisions, selection procedures, selection practices, selection } \\
\text { requirements }\end{array}$ \\
\hline Interviews & Competency-based interviews, job interview \\
\hline Technology issues & Multimedia, video-resumes, video-based SJT, video assessment, E-assessment \\
\hline Job analysis & Job classification, job description \\
\hline Job choice & Job choice \\
\hline Job search & Job search \\
\hline Contingent employees & Temps, probationary \\
\hline International/global issues & International, global \\
\hline Biographical data & Curriculum vitae, application forms, biodata \\
\hline Applicant reactions & applicant reactions/perceptions \\
\hline
\end{tabular}

